\title{
Time-dependent effects of late-onset dietary intake of salidroside on lifespan and age-related biomarkers of the annual fish Nothobranchius guentheri
}

\author{
Xia Wang ${ }^{1}$, Xiaoyuan Du ${ }^{1}$, Yang Zhou ${ }^{3}$, Su Wang ${ }^{1}$, Feng Su ${ }^{3}$ and Shicui Zhang ${ }^{1,2}$ \\ ${ }^{1}$ Institute of Evolution and Marine Biodiversity and Department of Marine Biology, Ocean University of China, Qingdao \\ 266003, China \\ ${ }^{2}$ Laboratory for Marine Biology and Biotechnology, Qingdao National Laboratory for Marine Science and Technology, Qingdao \\ 266003, China \\ ${ }^{3}$ Institute of Chemical Engineering, Qingdao University of Science and Technology, Qingdao 266042, China \\ Correspondence to: Feng Su, email: sufengvip@126.com \\ Shicui Zhang, email: sczhang@ouc.edu.cn
}

Keywords: salidroside; aging; lifespan; antioxidant system; Nothobranchius

Received: February 09, 2017 Accepted: November 20, 2017 Epub: January 04, 2018 Published: March 13, 2018

Copyright: Wang et al. This is an open-access article distributed under the terms of the Creative Commons Attribution License 3.0 (CC BY 3.0), which permits unrestricted use, distribution, and reproduction in any medium, provided the original author and source are credited.

\section{ABSTRACT}

One of the most studied and widely accepted conjectures of aging process is the oxidative stress theory. Previous studies have shown that salidroside can protect D-galactose-induced mouse model against aging and a formulation of Rhodiola rosea extracts (SHR-5) containing salidroside increases lifespan of fruit fly. However, direct evidence linking salidroside itself with the observed anti-aging effect in vivo and relevant molecular mechanisms are poorly defined. In this study, we first demonstrated that salidroside exhibited a time-dependent effect, and lateonset long-term salidroside dietary intake extended the lifespan in the annual fish Nothobranchius guentheri. We then showed that salidroside reduced the accumulation of lipofuscin in the gills as well as the levels of protein oxidation, lipid peroxidation and reactive oxygen species in the muscles; enhanced the activities of catalase, glutathione peroxidase, and superoxide dismutase in the fish; and decelerated the increase of P66shc, a critical factor for regulation of intracellular reactive oxygen species contents. Collectively, these data indicate that salidroside can prolong the lifespan and retard the onset of age-related biomarkers via the antioxidant system in aging fish. It also suggests that salidroside may have a potential usefulness in prolonging the lifespan of the elderly.

\section{INTRODUCTION}

Aging is the process of becoming older, which is exemplified by the progressive physiological changes in an organism that lead to a decline of biological functions and of the organism's ability to adapt to metabolic stress. One of the most studied and widely accepted conjectures on the molecular basis of aging process is the oxidative stress theory initially proposed by Denham Harman [1]. Oxidative stress, an imbalance in the production and detoxification of reactive oxygen species (ROS), the by-products of oxidative phosphorylation, causes damage to the macromolecules including lipids, proteins and DNA, and the organelles such as mitochondrion, thereby impairing cellular integrity and functionality, eventually resulting in progressive aging of organisms [2-5]. The theory has gained strong support from many studies that linked oxidative stress to longevity using model organisms including yeasts, flies, nematodes, and rodents $[2,6-8]$. Under this mechanistic framework, down-regulation of oxidative stress may be directly beneficial to the extension of health span and lifespan. Actually, numerous studies have proved that ingestion of ROS scavenger compounds, such as resveratrol, vitamin E, and ethosuximide, prolongs an organism's lifespan [9-13]. 
Salidroside (SDS), a phenylpropanoid glycoside, is a potent antioxidant component isolated from the roseroot Rhodiola rosea, which grows at high altitudes (up to 2280 $\mathrm{m})$ in the Arctic and mountainous regions throughout Europe and Asia, and has long been used as traditional medicine in China and Eastern Europe. The main effects of SDS described include anti-hypoxia, anti-inflammatory, anti-viral, anti-cancer, anti-fatigue, immune-boosting, hepatoprotective and neuroprotective activities [14-25]. Additional studies have also proved that SDS protects D-galactose-induced mouse model against aging [18] and a formulation of $R$. rosea extracts (SHR-5) containing SDS increases both mean and maximum lifespan of fruit fly [26]. However, direct evidence linking SDS itself with the observed anti-aging effect in vivo and relevant molecular mechanisms are still poorly defined.

Small annual fishes, especially the genus Nothobranchius, have many anatomical and histological characteristics similar to those of mammalian species and a relatively short lifespan, are commercially available, and are easily reared in captivity. Thus, they have become an emerging model organism for aging studies in recent years. For example, it has been demonstrated that senescenceassociated $\beta$-galactosidase, accumulation of lipofuscin (LF), levels of lipid peroxidation and protein oxidation increased with age, whereas the activities of anti-oxidant enzymes catalase (CAT), glutathione peroxidase (GPX), and superoxide dismutase (SOD) decreased with age in $N$. rachovii [27]. Additionally, resveratrol was found to be able to extend both the mean and maximum lifespans, to attenuate the increase of reactive oxygen species (ROS) and the degree of oxidative damage by up-regulating activities of anti-oxidant enzymes CAT, GPX and SOD and to preserve glia in $N$. guentheri $[11,28]$. Moreover, vertebrate aging-related genes $p 66 \mathrm{Shc}$ and microsomal triglyceride transfer protein (MTP) could be easily isolated by homology cloning in $N$. furzeri [29]. In this study, we thus used the annual fish Nothobranchius guentheri as model to explore if dietary intake of SDS has any influence on aging kinetics by determination of several age-related biomarkers such as antioxidant systems, and if so, to illustrate the possibly associated molecular mechanisms.

\section{RESULTS}

\section{SDS has little effects on body weight and length}

Totally, 190 of 9-month-old male $N$. guentheri were divided into two groups, and fed with the SDS-containing and control diets, respectively. All the fish survived well, and little difference was observed in the behavior and locomotive activity between the fishes in the two groups throughout the experimental periods.

Both the body weight and length were assessed on 38th, 42th and 46th weeks. Compared with control group, no significant differences were observed in the body weight and length of the fish in SDS group (Figure 1A, 1B; $p>0.05$ ), consistent with the observation of Lu et al. [17]. These show that SDS administration has little influence on the body weight and length of aging $N$. guentheri.

\section{SDS prolongs lifespan}

Survivorship curves for 9-month-old (36 weeks) male $N$. guentheri of the control and SDS groups showed that the mean lifespans of the fishes in SDS and control groups were $51.5 \pm 1.3$ and $47.5 \pm 1.6$ weeks $(p<0.05$; Figure 2), respectively. In accordance, the maximum lifespans of the fishes in the two groups were $56 \pm 1.2$ and $53 \pm 1.4$ weeks $(p<0.05)$, individually. Obviously, SDS extended the mean and maximum lifespans of the fishes by approximately 4 and 3 weeks, separately. Therefore, late-onset SDS administration is able to prolong the survivorship of male $N$. guentheri.

\section{SDS reduces accumulation of $L F$ in gills}

LF is visualized as bright green-colored autofluorescent dots in the gill cells. As shown in Figure 3 and Supplementary Table 1, SDS administration for 7 weeks
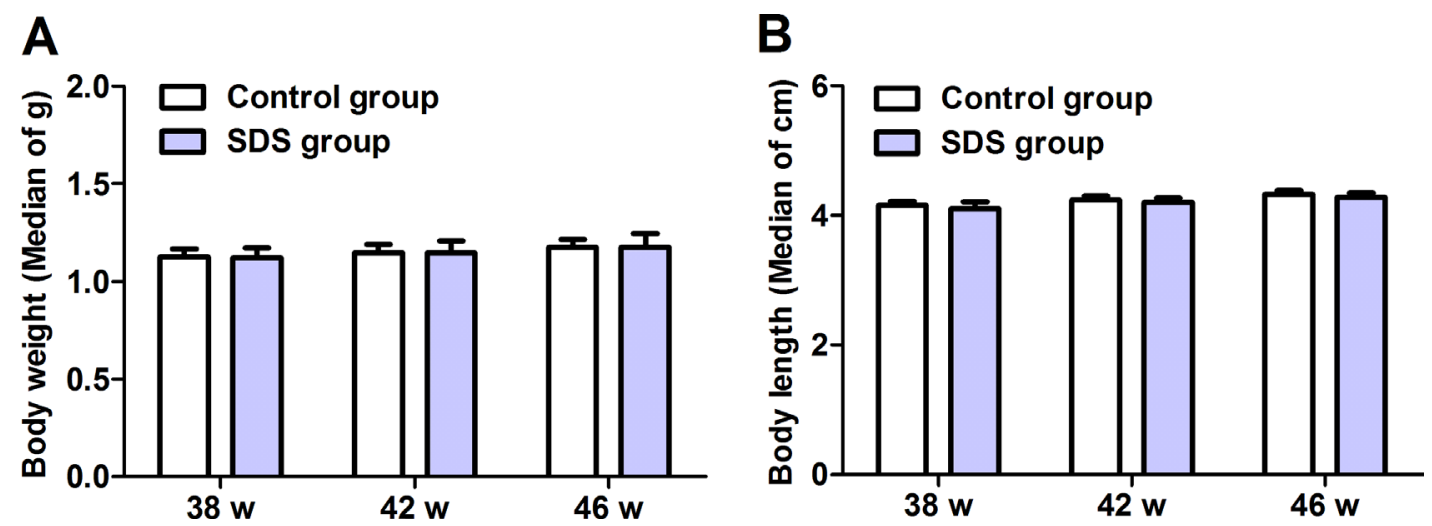

Figure 1: Body weight (A), body length (B) of male $N$. guentheri. The values of body weight are median of $\mathrm{g} \pm \mathrm{standard}$ deviation (SD) $(n=4)$, and the values of body length are median of $\mathrm{cm} \pm$ standard deviation (SD) $(n=4)$. The data are from 4 independent experiments which were performed in triplicate. w, week. 
(from 36th to 42th week) resulted in little difference in the green-colored areas in the gills of the fish, compared with control group $(3.525 \pm 0.0118 \%$ vs $4.168 \pm 0.0701 \%$; $6.348 \pm 0.1563 \%$ vs $7.718 \pm 0.1846 \% ; p>0.05)$, but SDS administration for 10 weeks (from 36th to 46th week) caused significant reduction $(8.19 \pm 0.6601 \%$ vs 12.86 $\pm 1.765 \% ; p<0.05)$ in the fluorescent areas in the gills of the fishes of SDS group than control group. These indicate that the effects of SDS are time-dependent, and longer term SDS administration (e.g. 10 weeks) reduces the accumulation of LF in the gills of aging $N$. guentheri.

\section{SDS reduces levels of protein oxidation and lipid peroxidation}

The contents of carbonyl-group (protein oxidation marker) and malondialdehyde (MDA, a metabolite of lipid peroxidation) acquired by the muscles were detected on 38th, 42th and 46th weeks. Little differences were found between the mean values of carbonyl-group content in the muscles of the fishes of SDS group $(21.17 \pm 0.137$ $\mathrm{nmol} / \mathrm{mg}$ protein) and control group (21.49 $\pm 0.318 \mathrm{nmol} /$ $\mathrm{mg}$ protein; $p>0.05$; Figure $4 \mathrm{~A}$ ) on 38 th week, while the mean values of carbonyl-group content in the muscles of the fish of SDS group were considerably decreased on 42th and 46th weeks, compared with control group (22.04 \pm 0.710 vs $24.20 \pm 0.548,23.37 \pm 1.763$ vs $27.58 \pm 0.633$ $\mathrm{nmol} / \mathrm{mg}$ protein; $p<0.05$; Figure $4 \mathrm{~A}$ ). Similarly, on 38 th week, the mean values of MDA in the muscles of the fish of SDS group $(3.401 \pm 0.014 \mu \mathrm{M} / \mathrm{mg}$ protein) were not different from those in the muscles of the fish of control group $(3.431 \pm 0.038 \mu \mathrm{M} / \mathrm{mg}$ protein; $p>0.05$; Figure $4 \mathrm{~B})$, whereas the mean values of MDA in the muscles of the fish of SDS group were markedly reduced on 42th and 46th week, compared with control group $(3.469 \pm 0.032 \mathrm{vs}$ $3.654 \pm 0.034$, and $3.677 \pm 0.0619$ vs $3.919 \pm 0.056 \mu \mathrm{M} /$ mg protein; $p<0.05$; Figure 4B). These show again that the effects of SDS are time-dependent, and longer term SDS administration reduces the levels of both carbonylgroup and MDA in the muscles of aging $N$. guentheri.

\section{SDS prevents decrease in CAT, GPX and SOD activities}

Figure 5 shows the changes in the activities of antioxidant enzymes CAT, GPX and SOD. On 38th week, the mean values of CAT, GPX and SOD activities in the muscles of the fish of SDS group were closely similar to those in the muscles of control fish $(p>0.05)$. By contrast, on 42th and 46th weeks, the mean values of CAT, GPX and SOD activities in the muscles of the fish of SDS group were significantly increased, compared with control group (for CAT: $3.133 \pm 0.101$ vs $2.950 \pm 0.077$ and $2.698 \pm$ 0.052 vs $2.481 \pm 0.065 \mu \mathrm{M} / \mathrm{min} / \mathrm{mg}$ protein; for $\mathrm{GPX}$ : $6.836 \pm 0.929$ vs $6.529 \pm 0.907$ and $6.320 \pm 0.950$ vs 5.735 $\pm 0.891 \mathrm{nM} / \mathrm{min} / \mathrm{mg}$ protein; for SOD: $21.48 \pm 1.847 \mathrm{vs}$ $20.53 \pm 1.797$ and $17.69 \pm 0.227$ vs $15.89 \pm 0.140 \mathrm{U} / \mathrm{mg}$ protein; $p<0.05)$. These indicate that longer term but not shorter term (e.g. 3 weeks) SDS administration prevents the decrease in the activities of the anti-oxidant enzymes.

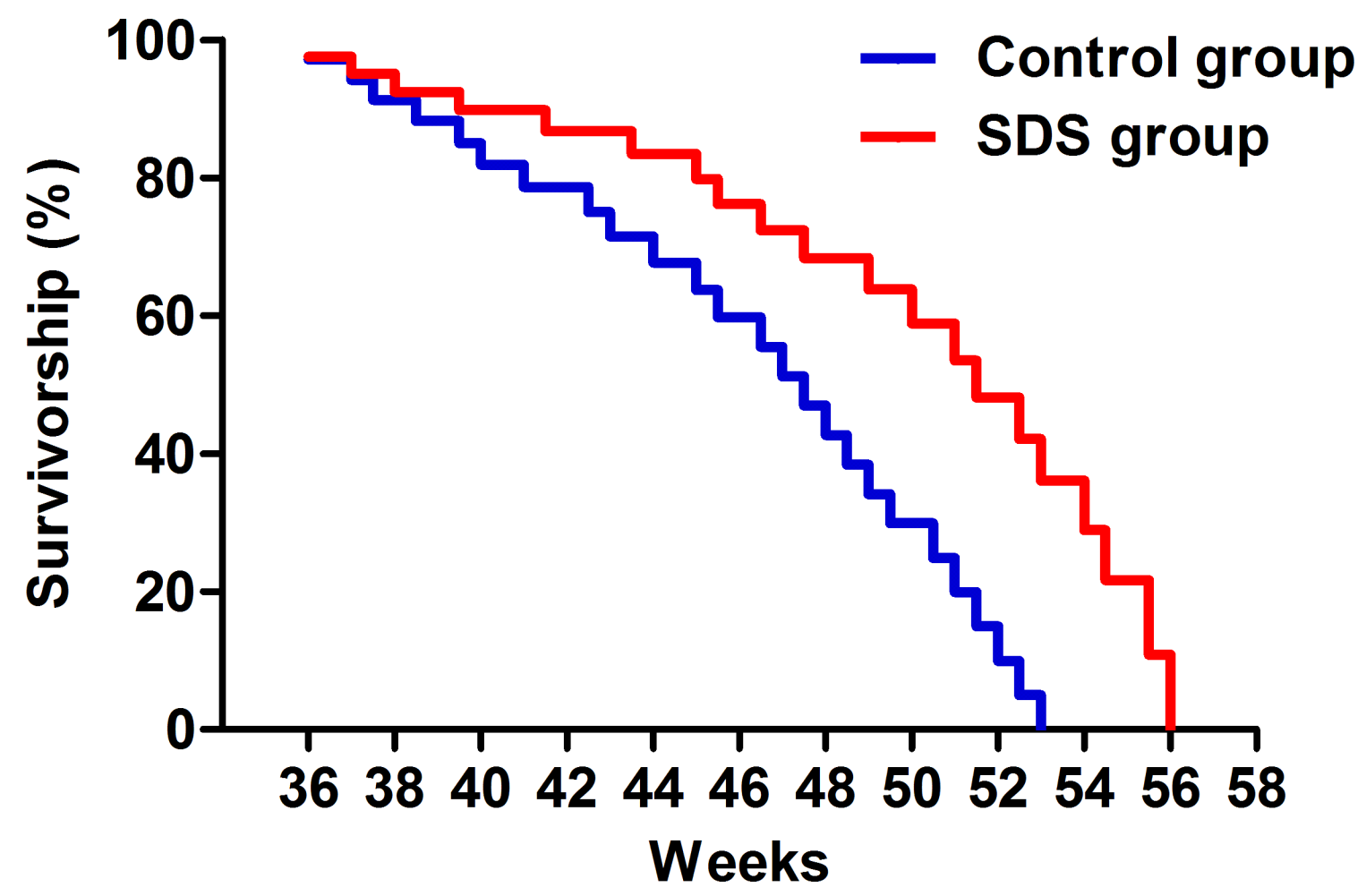

Figure 2: Survivorship curve. The survivorship curves of male N. guentheri in control ( $n=50$; blue line) and SDS groups $(n=50$; red line) $(p<0.05)$. 


\section{SDS down-regulates expression of p66she}

Intracellular ROS contents can be increased by three main mechanisms: reducing ROS scavenging, increasing membrane oxidases activity, or by mitochondrial respiratory chain leakage; and $\mathrm{P} 66 \mathrm{SHC}$ has been shown to act through all the three mechanisms. Therefore, $N$. guentheri P66she cDNA was cloned and qRT-PCR was used to examine the expression profiles of $p 66 \mathrm{shc}$ in the fish. $N$. guentheri P66shc cDNA sequence we obtained was about $1785 \mathrm{bp}$, coding for a protein of 595 amino acids with a molecular mass of about $64 \mathrm{kDa}$ (Supplementary Figure 2). N. guentheri P66shc, like mammalian P66SHC, both had four conserved domains $\mathrm{CH} 2, \mathrm{PTB}, \mathrm{CH} 1$ and $\mathrm{SH} 2$, three highly conserved $\mathrm{S}$ residues and a conserved cytochrome $\mathrm{c}$ binding domain consisting of $\mathrm{E}, \mathrm{D}$ and $\mathrm{W}$ residues (Supplementary Figure 3). Sequence alignment showed that $N$. guentheri P66she was $70 \%$ to $71.5 \%$ identical to mammalian P66SHC at amino acid levels (Supplementary Figure 4).

The dissociation curve of amplified product showed a single peak, indicating that the amplification was specific (data not shown). On 38th and 42th weeks, mRNA levels of p66shc in the muscles of the fish of SDS group were similar to those in the muscles of control fish $(p>0.05)$. By contrast, on 46th week, mRNA content of p66shc in the muscles of the fish of SDS group was remarkably decreased, compared with control group ( $p<$ 0.05 ; Figure $6 \mathrm{~A}$ ). These results were also confirmed by Western blotting analysis. To obtain a positive control, His-tagged $N$. guentheri P66shc was first expressed in
HEK 293T cells. As shown in Figure 6B (the entire gels of Western blotting were shown in Supplementary Figure 5), the extracted proteins of HEK 293T cells with $p c D N A 3.1 /$ V5/p66shc/His reacted with anti-His tag antibody as well as with anti-SHC antibody, both producing a main band of about $69 \mathrm{kDa}$. These indicated that anti-SHC antibody was specific to P66shc. Next, we used the anti$\mathrm{SHC}$ antibody to detect the expression of P66shc in $N$. guentheri muscles, and found that only a single band of about $64 \mathrm{kDa}$ was visualized, which apparently represents $N$. guentheri P66shc (Figure 6C and 6D; the entire gels of Western blotting were shown in Supplementary Figure 6). Notably, no significant differences were observed between the contents of P66shc in the muscles of the fishes of SDS and control groups $(p>0.05)$ on 38th and 42th weeks, but on 46th week, the P66shc level in the muscles of the fish of SDS group was markedly decreased, compared with control group ( $p<0.05$; Figure $6 \mathrm{C}$ and $6 \mathrm{D})$ ). These show that longer term SDS administration accelerates the decrease in P66shc in aging $N$. guentheri.

\section{SDS reduces level of ROS}

Next, we measured the levels of ROS in the muscles on 38th, 42th and 46th weeks. As shown in Figure 7, the levels of ROS in the muscles of the fish of control group were $413.7 \pm 15.32,450.4 \pm 10.05$, and $506.9 \pm 15.38$ fluorescence intensity/mg protein on 38th, 42th and 46th weeks, respectively. By contrast, the levels of ROS in the muscles of the fish of SDS group were $403.7 \pm 15.23$, $430.4 \pm 10.0$ and $480.4 \pm 20$ fluorescence intensity $/ \mathrm{mg}$

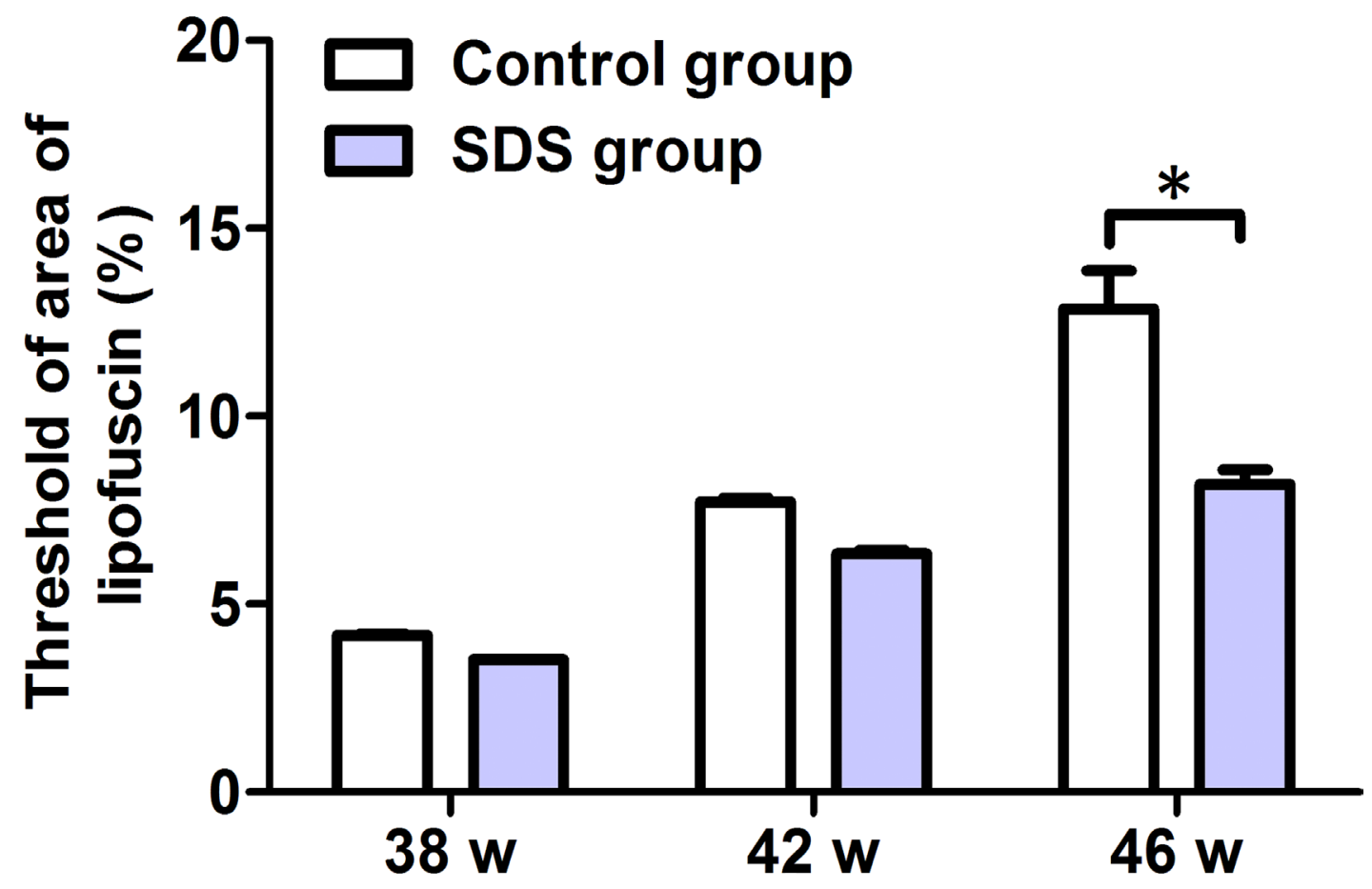

Figure 3: Changes of the histological marker LF in 38-, 42- and 46-week-old $\boldsymbol{N}$. guentheri. Statistical analysis of the threshold of areas occupied by LF in the gills of $N$. guentheri according to Supplementary Figure $3(n=4)$. The data are from 4 independent experiments which were performed in triplicate. The symbol $\left(^{*}\right)$ means significantly different $(p<0.05)$. w, week. 
protein on 38th, 42th and 46th weeks, individually. It was clear that ROS levels decreased significantly in the muscles of the fish in SDS group than control group on 38 th, 42th and 46th weeks $(p<0.05)$. These show that SDS decreases ROS levels in the muscles of aging $N$. guentheri.

\section{DISCUSSION}

The phenotype of an organism, which includes characteristics such as lifespan, is determined in part by the nucleotide sequence of its genes and in part by the regulation of these genes, which is often influenced by the genome as well as the environment. Therefore, nonintrusion interventions, such as calorie restriction (CR) and temperature reduction (TR), as well as nutritional interventions with essential nutrients or functional foods, are also identified as possible approaches for prolonging an organism's life span. For example, dietary supplementation with nutrients with antioxidant properties, such as $\beta$-carotene, vitamin $\mathrm{E}$, and lycopene, has been shown to improve immune function in aged mice and humans [30-32]. Dietary intake of SDS has been shown to protect $\mathrm{PC} 12$ cells against $\mathrm{H}_{2} \mathrm{O}_{2}$-induced apoptosis [33] and HaCAT cells against UVB-mediated oxidative damage [34]. SDS has also been reported to alleviate oxidative stress in the liver with non-alcoholic steatohepatitis in rats [35], to prevent kainic acidinduced status epilepticus via suppressing oxidative stress and diabetes-induced oxidative stress in mice [36, 37], and to protect mitochondria against exertional heat stroke-induced organ damage and retinal endothelial cells against hydrogen peroxide-induced injury via modulating oxidative status and apoptosis in rats [38, 39]. The main findings of our study are that late-onset SDS administration does not reduce the body weight and length of aging $N$. guentheri, but it is able to decrease the agerelated markers and increase the median and maximum lifespans of the fish. SDS appears to perform this antiaging activity via action of antioxidant system. Our results clearly demonstrate that SDS can enhance the activities of

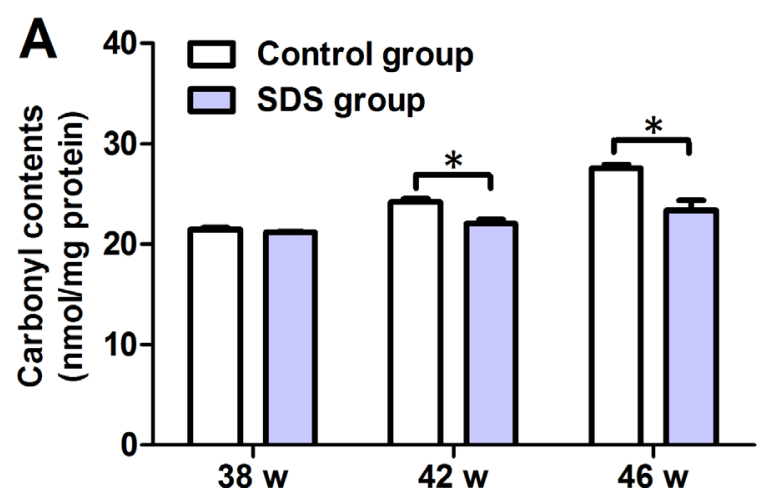

the anti-oxidant enzymes, and reduce the level of P66shc, a potent factor responsible for regulation of intracellular ROS contents. Both the enhanced antioxidant enzyme activities and reduced P66shc level may directly lead to the reduction of ROS levels (Figure 8), which in turn slow down the protein oxidation, lipid peroxidation and possibly LF development, and eventually prolong the lifespan of aging fish.

SDS has been highly valued for many years for its anti-hypoxia, health-promoting, immune-boosting and anti-aging abilities, but studies to evaluate the time course of SDS effects remains lacking. An interesting finding of this study is that the effects of SDS are time-dependent. We demonstrate here that dietary intake of SDS for 3 weeks (from 36th to 38th week) has little effects on the parameters examined, including LF, lipid peroxidation, protein oxidation, CAT, GPX, SOD, and P66shc, but 10 week SDS administration (from 36th to 46th week) resulted in a marked decrease in the levels of LF, lipid peroxidation, protein oxidation, P66Sshc and ROS as well as a remarkable increase in the activities of antioxidant enzymes CAT, GPX and SOD. These suggest that SDS may prolong the lifespan of aging $N$. guentheri in a timedependent fashion, and relatively longer term dietary intake is necessary for lifespan extension.

In summary, this study highlights the anti-aging property of SDS and its potential usefulness in prolonging the lifespan of aging fish (and possibly the elderly). It also shows for the first time that the anti-aging effects of SDS are time-dependent.

\section{MATERIALS AND METHODS}

\section{Fish culture and diet}

All the fish $N$. guentheri used in the experiments were treated in accordance with the guidelines of the Laboratory Animal Administration Law of China, with the permit number SD2007695 approved by the Ethics Committee of the Laboratory Animal Administration of Shandong province. The fish $N$. guentheri were bred in our

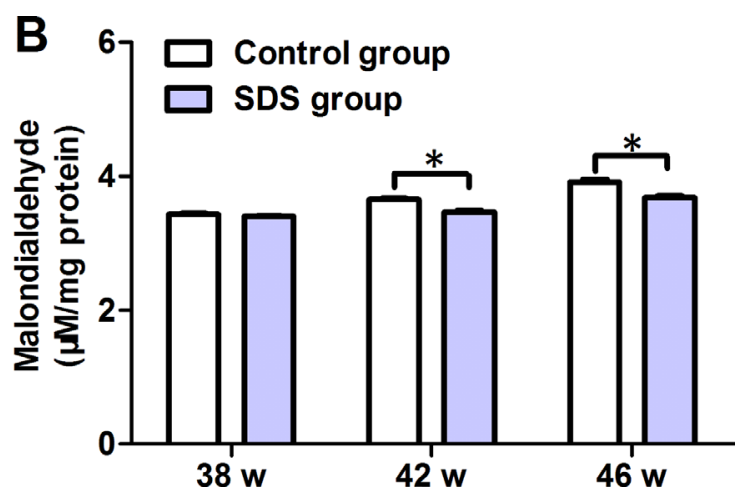

Figure 4: The levels of protein oxidation and lipid peroxidation in 38-, 42- and 46-week-old $N$. guentheri in control and SDS groups. (A) Protein oxidation levels; (B) Lipid peroxidation levels. Data represent mean \pm standard deviation (SD) $(n=4)$. The data are from 4 independent experiments which were performed in triplicate. The symbol $\left(^{*}\right)$ means significantly different $(p<0.05)$. w, week. 
own laboratory. It has a relatively stable lifespan. We have shown a complete survival curve of $N$. guentheri produced in our lab in Supplementary Figure 7. All of the fish were reared at a density of 5 fishes per 10-liter tank under an ambient photoperiod at $26 \pm 1{ }^{\circ} \mathrm{C}$, and fed with live blood worms twice a day. As the male $N$. guentheri have median survival of approximately 12 months [40], thus the 9-month-old (i.e. 36th week) male fish were selected as model of aging fish in order to test the effect of SDS on aging process in this study.

The dried food was prepared as described by Valenzano et al. [13]. Briefly, the blood worms were left to drip dry, and then $20 \mathrm{mg} / \mathrm{ml} \mathrm{SDS}$ (purity $>98 \%$; MANSITE BIO-TECHNOLOGY, China) dissolved in distilled water was added to the dry worms. The worms were equally divided into several pieces, each piece was added with the same SDS at a dose of $24 \mathrm{mg} / \mathrm{kg}$ of body weight and stored at $4^{\circ} \mathrm{C}$ for $2 \mathrm{~h}$ to soak. The worms with or without SDS were mixed with $5 \%$ gelatin and frozen at $-20^{\circ} \mathrm{C}$ until use. Each fish was fed with one piece of the worms every day. The SDS was wrapped with gelatin and it did not dissolve in water easily, thus each fish could eat the whole piece of the worms and obtain the same quantity of SDS. The SDS-containing dried worms were named experimental diet, and the worms without SDS control diet. Totally, 190 individuals of 9-monthold male fish with average body weight of about $1.1 \mathrm{~g} /$ per fish were equally divided into two groups: one group

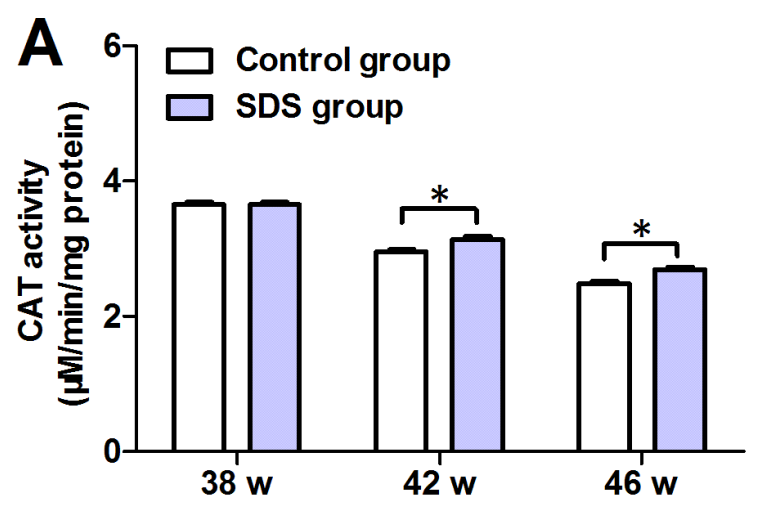

of fish was fed with $40 \mathrm{mg}$ experimental diet/g fish weight/day every day, with SDS at a dose of $24 \mathrm{mg} / \mathrm{kg}$ of body weight (The quantity of the diet was consumed by fish in a 15-min period, leaving no uneaten food); and the other group fed with $40 \mathrm{mg}$ control diet/g fish weight/day every day. One hundred (50/each group) out of 190 fish were continuously cultured for assays of survivorship, body weight, and body length (Figure 9). The remaining 90 fish (45/each group) were cultured, and 12 fish were sampled from each group on 38th, 42th and 46th weeks (Figure 9), and anesthetized by cooling on ice. The 12 fish were divided into 3 sub-groups, each containing 4 individuals (Supplementary Table 1). The gills, muscles and fish body (FB) from the pectoral fin to tail fin containing only bones and red and white muscles (excluding head and internal organs) were dissected out of the fish of each sub-group, pooled and used for the following experiments.

\section{Survivor observation and body weight and length measurement}

The health of each fish in the experimental (SDS) and control groups was surveilled every day, and the survival of fish was recorded until death of all the fish. Body weight and body length of fish were measured on 38th, 42th and 46th weeks respectively, as described by Markofsky and Perlmutter [41].

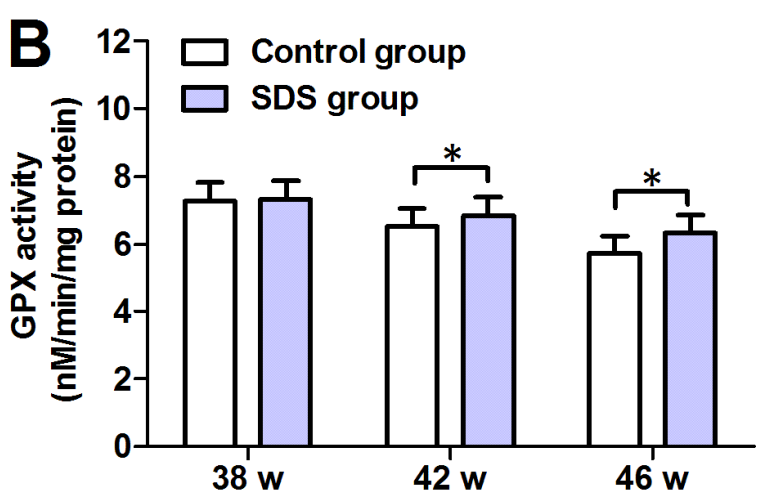

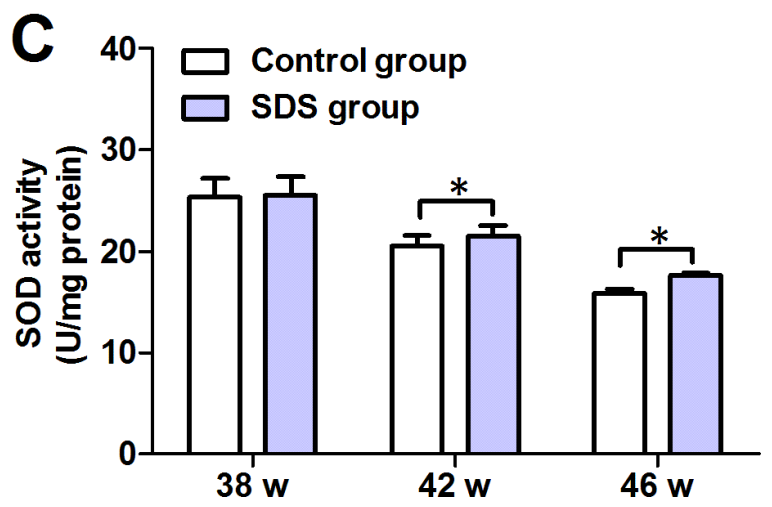

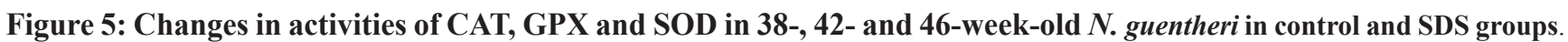
(A) CAT activities; (B) GPX activities; (C) SOD activities. Data represent mean \pm standard deviation (SD) $(n=4)$. The data are from 4 independent experiments which were performed in triplicate. The symbol $\left(^{*}\right)$ means significantly different $(p<0.05)$. w, week. 


\section{Assay for histological marker}

The gills were fixed in $4 \%$ formaldehyde in phosphate-buffered saline (PBS) at $4^{\circ} \mathrm{C}$ overnight, and precipitated in a $30 \%$ sucrose solution. They were embedded in optical cutting temperature compound, and sectioned at $10 \mu \mathrm{m}$ thickness under $-20^{\circ} \mathrm{C}$ (Leica, Germany). The auto-fluorescence of LF was observed under a fluorescence microscope with blue (450-490 $\mathrm{nm}$ ) excitation light and $520 \mathrm{~nm}$ emission filter, and the fluorescent areas were quantified by Image J software [11].

\section{Assay for protein oxidation}

The protein oxidation assay followed the method of Sohal et al [42]. A total of 1 gram of the muscle, including red and white ones, from 4 freshly killed fish was homogenized in $5 \mathrm{ml}$ of $50 \mathrm{mM}$ PBS (pH7.5) containing the protease inhibitors (leupeptin at $0.5 \mathrm{mg} /$ $\mathrm{ml}$, aprotinin at $0.5 \mathrm{mg} / \mathrm{ml}$, pepstatin at $0.7 \mathrm{mg} / \mathrm{ml}$, and phenylmethylsulfonyl fluoride [PMSF] at $40 \mathrm{mg} / \mathrm{ml}$ ) using a Polytron and sonicator. The homogenates were centrifuged at $5000 \mathrm{~g}$ at $4^{\circ} \mathrm{C}$ for $10 \mathrm{~min}$. The protein concentration of the supernatants was determined with a BCA Protein Assay Kit. Aliquots of $300 \mu \mathrm{l}$ of the resulting supernatants with 2 to $2.5 \mathrm{mg}$ of protein were treated with $300 \mu \mathrm{l}$ of $10 \mathrm{mM} \mathrm{2,4-dinitrophenylhydrazine} \mathrm{(DNPH)}$ dissolved in $2 \mathrm{M} \mathrm{HCl}$ or $2 \mathrm{M} \mathrm{HCl}$ alone (control). The mixtures were incubated at room temperature for $1 \mathrm{~h}$ (with agitation every $10 \mathrm{~min}$ ), precipitated with $10 \%$ trichloroacetic acid (final concentration), and centrifuged at $12000 \mathrm{~g}$ at $4^{\circ} \mathrm{C}$ for $15 \mathrm{~min}$. The pellets were washed three times with $1 \mathrm{ml}$ of ethanol/ethyl acetate ( $\mathrm{vol} / \mathrm{vol} 1: 1$ ) and re-dissolved in $1 \mathrm{ml}$ of $6 \mathrm{M}$ guanidine in $10 \mathrm{mM}$ PBS/ trifluoroacetic acid $(\mathrm{pH} 2.3)$. Any trace insoluble material was removed by centrifugation at $12000 \mathrm{~g}$ for $15 \mathrm{~min}$. The difference in absorbance between the DNPH- and $\mathrm{HCl}$-treated materials was determined at $366 \mathrm{~nm}$, and expressed as nanomoles of carbonyl groups per milligram of protein, using the excitation coefficient of $22 \mathrm{mM}^{-1} \mathrm{~cm}^{-1}$ for aliphatic hydrazones.

\section{Assay for lipid peroxidation}

To estimate lipid peroxidation levels, a lipid peroxidation MDA Assay Kit (Beyotime, China) was used to quantify the generation of MDA [43]. In brief, 1 gram of the fish body, FB (from 4 fish), was homogenized in 10 $\mathrm{ml}$ of $50 \mathrm{mM}$ PBS (pH7.5) using a Polytron and sonicator. The homogenates were centrifuged at $5000 \mathrm{~g}$ at $4^{\circ} \mathrm{C}$ for 10 $\mathrm{min}$, and the protein concentration of the supernatants was determined with a BCA Protein Assay Kit. Aliquots of 100 $\mu \mathrm{l}$ supernatants with $2 \mathrm{mg}$ of protein were mixed with 200 $\mu \mathrm{l}$ of thiobarbituric acid (TBA) working solution in a test tube, and the mixtures incubated in a boiling water bath for $15 \mathrm{~min}$. After cooling in tap water, the mixtures were
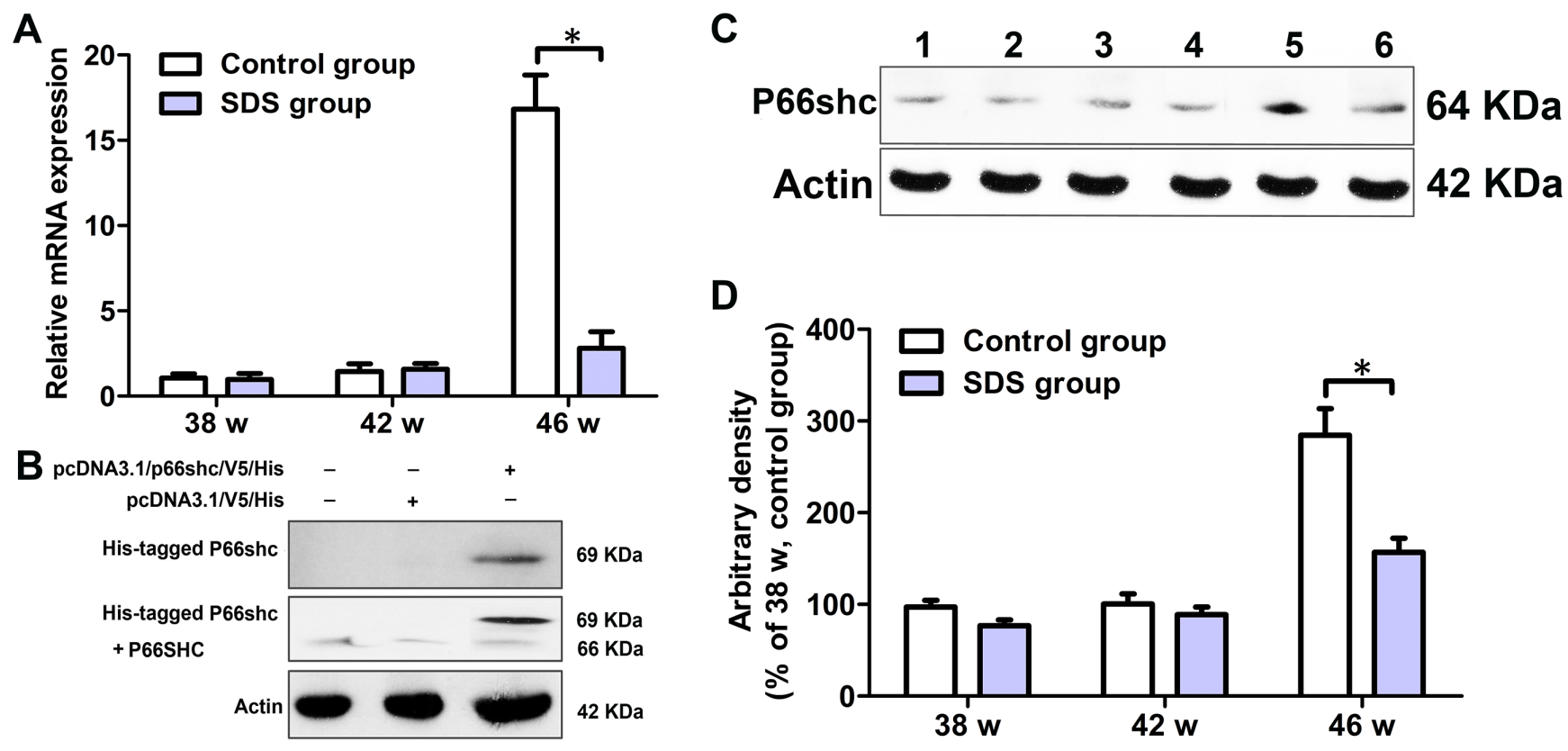

Figure 6: Levels of p66shc in the muscles of 38-, 42- and 46-week-old $N$. guentheri in control and SDS groups. (A) Expression profile of $p 66 \mathrm{shc}$. $\beta$-actin gene was chosen as the internal control for normalization. Relative expression data were calculated by the method

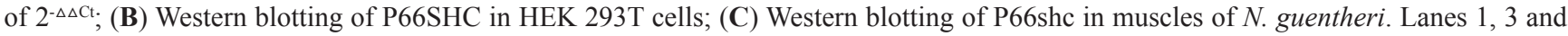
5, protein extracts from 38, 42 and 46-week-old $N$. guentheri muscles in control group; Lanes 2, 4 and 6, protein extracts from 38, 42 and 46-week-old N. guentheri muscles in SDS group; (D) Expression of P66shc in $N$. guentheri muscles were normalized to expression in 38 -week-old $N$. guentheri muscles in control group. $\beta$-Actin was chosen as the internal control for normalization. Data represent mean \pm standard deviation $(\mathrm{SD})(\mathrm{n}=4)$. The data are from 4 independent experiments which were performed in triplicate. The symbol $\left({ }^{*}\right)$ means significantly different $(p<0.05)$. w, week. 
centrifuged at $1000 \mathrm{~g}$ for $10 \mathrm{~min}$, and their absorbances measured at $532 \mathrm{~nm}$. The concentration of MDA was expressed as micromoles per gram of protein [44].

\section{Assay for CAT}

CAT activity was estimated as described by Hsu et al. [27]. Aliquots of $1 \mathrm{~g} \mathrm{FB}$ (from 4 fish) were homogenized in $10 \mathrm{ml}$ of $50 \mathrm{mM}$ PBS (pH7.5) using a Polytron and sonicator, and the homogenates prepared as above. The assay reaction consisted of $50 \mathrm{mM}$ PBS (pH7.5), $100 \mu \mathrm{l}$ of $30 \%$ hydrogen peroxide $\left(\mathrm{H}_{2} \mathrm{O}_{2}\right)$, and the resulting supernatants in a total volume of $1 \mathrm{ml}$. The reaction was carried out at $25^{\circ} \mathrm{C}$. A blank control was prepared with $900 \mu \mathrm{l}$ of $50 \mathrm{mM}$ PBS and $100 \mu \mathrm{l}$ of $30 \%$ $\mathrm{H}_{2} \mathrm{O}_{2}$. The rates of absorbance change $(\Delta \mathrm{A} / \mathrm{min})$ at 240 $\mathrm{nm}$ were recorded, which indicated the decomposition of $\mathrm{H}_{2} \mathrm{O}_{2}$. CAT activities were calculated using the molar extinction coefficient of $\mathrm{H}_{2} \mathrm{O}_{2}$ at $240 \mathrm{~nm}, 43.59 \mathrm{I} / \mathrm{mol} \mathrm{cm}$. Units of CAT were expressed as the amount of enzyme that decomposes $1 \mu \mathrm{mol}$ of $\mathrm{H}_{2} \mathrm{O}_{2}$ per min at $25^{\circ} \mathrm{C}$. The specific activity was expressed in terms of micromoles per minute per milligram of protein.

\section{Assay for GPX}

GPX activity assay was measured by the method of Hsu et al. [27]. Briefly, aliquots of $1 \mathrm{~g} \mathrm{FB}$ (from 4 fish) were homogenized in $10 \mathrm{ml}$ of $50 \mathrm{mM}$ Tris- $\mathrm{HCl}$ buffer ( $\mathrm{pH} 7.5)$ containing the protease inhibitors $(0.5 \mu \mathrm{g} /$ $\mathrm{ml}$ leupeptin, $0.5 \mu \mathrm{g} / \mathrm{ml}$ aprotinin, $0.7 \mu \mathrm{g} / \mathrm{ml}$ pepstatin, $40 \mu \mathrm{g} / \mathrm{ml}$ PMSF) using a Polytron and sonicator, and the homogenates prepared as above. An aliquot of $10 \mu \mathrm{l}$ supernatant with $0.5 \mathrm{mg}$ of protein was mixed with $10 \mu \mathrm{l}$ of GPX working solution (5 $\mathrm{mM}$ nicotinamide adenine dinucleotide phosphate [NADPH], $42 \mathrm{mM}$ reduced glutathione, and $20 \mathrm{U}$ glutathione reductase), and then with $176 \mu \mathrm{l}$ GPX assay buffer (50 mM Tris- $\mathrm{HCl}$ containing 2 mM EDTA, pH7.5). All the solutions were pre-incubated at $25^{\circ} \mathrm{C}$ before mixing. The reaction was initiated by adding $4 \mu \mathrm{l}$ of $15 \mathrm{mM}$ tert-butyl-hydroperoxide (t-Bu-OOH; Beyotime, China) in Milli-Q-grade water. The absorbance (optical density [OD]) was recorded at $340 \mathrm{~nm}$ every 30 sec. One unit of GPX activity was defined as the amount of enzyme that hydrolyzes $1.0 \mu \mathrm{mol}$ of NADPH into $\mathrm{NADP}^{+}$ per minute under the conditions described [45].

\section{Assay for total SOD}

The assay of SOD was based on the reduction of nitroblue tetrazolium (NBT) to water-insoluble blue formazan [46]. Briefly, $1 \mathrm{~g}$ of FB (from 4 fish) was homogenized in $10 \mathrm{ml}$ of $50 \mathrm{mM}$ PBS (pH7.5) using a Polytron and sonicator. The homogenate was centrifuged at $5000 \mathrm{~g}$ at $4^{\circ} \mathrm{C}$ for $10 \mathrm{~min}$, and the supernatant was pooled. Total SOD activity was assayed according to the instructions of the SOD Assay Kit (Beyotime, China). The rate of NBT reduction was monitored at $560 \mathrm{~nm}$ at $25^{\circ} \mathrm{C}$. One unit of SOD was defined as the amount of protein that resulted in $50 \%$ inhibition of the rate of NBT reduction.

\section{Gene fragment cloning and quantitative real- time PCR (qRT-PCR)}

The muscles dissected out of freshly killed $N$. guentheri were ground in RNAiso Plus (TaKaRa) and

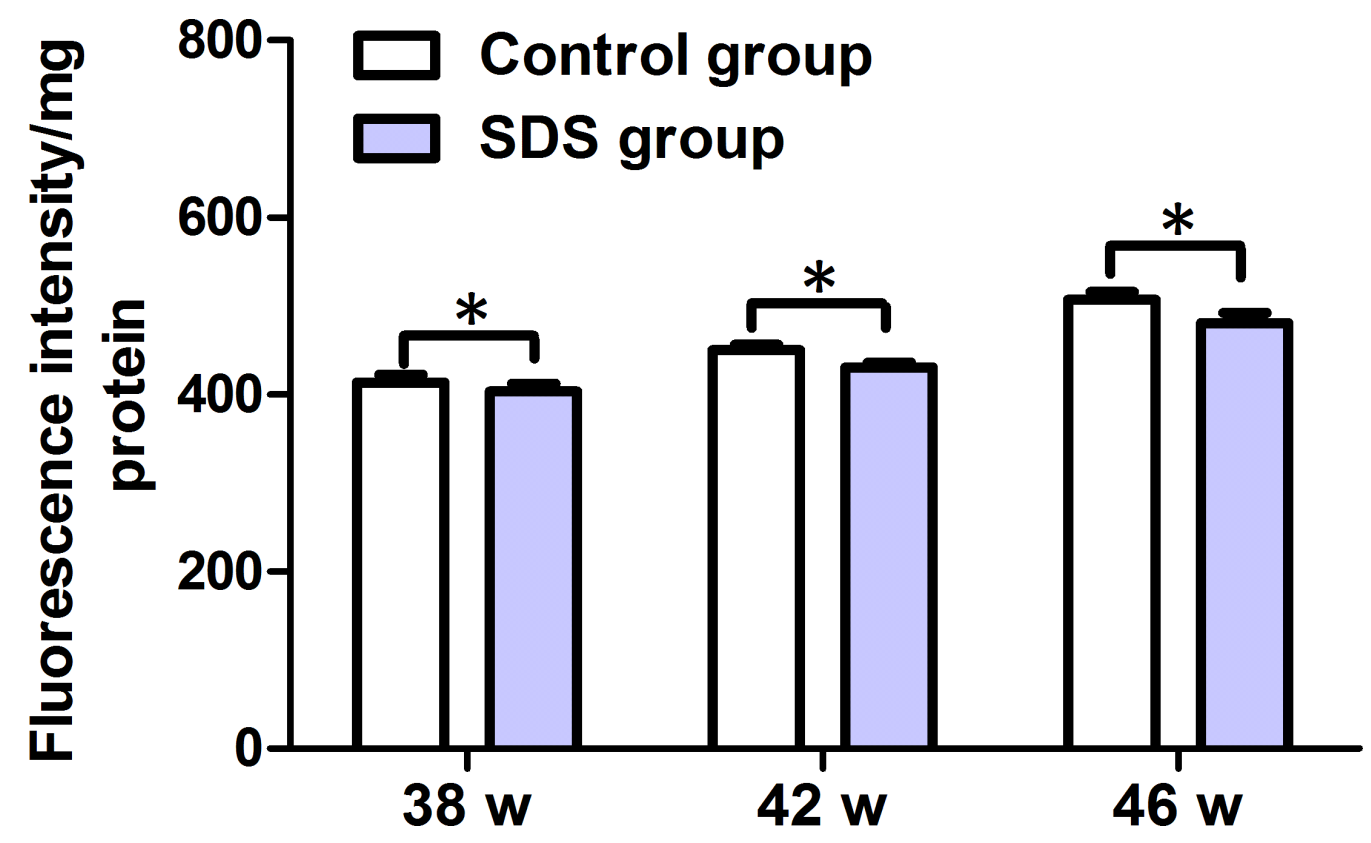

Figure 7: ROS levels in the muscles of 38-, 42- and 46-week-old $N$. guentheri in control and SDS groups. Data represent mean \pm standard deviation (SD) $(n=4)$. The data are from 4 independent experiments which were performed in triplicate. The symbol $\left(^{*}\right)$ means significantly different $(p<0.05)$. w, week. 
kept at $-70^{\circ} \mathrm{C}$ until use. Total RNAs were isolated from the frozen samples according to the manufacturer's instructions. After digestion with recombinant DNase I (RNase free; TaKaRa) to eliminate the genomic contamination, cDNAs were synthesized with a reverse transcription kit (TaKaRa) with oligo (dT) primer. The reaction was carried out at $42^{\circ} \mathrm{C}$ for $1 \mathrm{~h}$ and inactivated at $75^{\circ} \mathrm{C}$ for $15 \mathrm{~min}$. The cDNAs were stored at $-20^{\circ} \mathrm{C}$ till used [43].

For cloning of the gene p66shc, a pair of genespecific primers PS and PA (Table 1) was designed on the basis of $p 66 \mathrm{shc}$ gene sequence using the Primer Premier program (version 5.0), and used for PCR. The amplification products were cloned into a pGEM-T Easy vector (TIANGEN) following the manufacturer's instructions and transformed into Trans $5 \alpha$ bacteria (TRANSGEN). The positive clones were selected and sequenced using an ABI PRISM 3730 DNA sequencer. The sequences were compared with related sequences available in GenBank using BLASTx. The sequence of p66shc we obtained was deposited in GenBank and the accession number is: MF346704. To compare the similarity of $N$. guentheri P66shc with mammalian ortholog P66SHC, homology searches in the GenBank ${ }^{\mathrm{TM}}$ database were carried out using the BLAST server, and multiple alignments of the protein sequences generated using the Clustal W program [47] within MegAlign of the DNASTAR software package.

To detect the expression profiles of p66shc in the muscles from fish fed with the different diets, qRTPCR was performed using the first-strand cDNAs as template, which was reverse-transcribed from the total RNAs extracted from the muscles. One pair of primers specific of p66shc (qPS and qPA; Table 1) was designed using the Primer Premier program (version 5.0). The reaction mixture (final volume $20 \mu \mathrm{l}$ ) consisted of $10 \mu \mathrm{l}$ of SYBR Premix Ex Taq (Tli RNaseH Plus), $0.4 \mu \mathrm{l}$ ROX Reference Dye II, $0.5 \mu \mathrm{l}$ of template, and $200 \mathrm{nM}$ each of sense and antisense primers. The $\beta$-actin gene was chosen as the reference for internal standardization. All the qRT-PCR experiments were conducted in triplicate. The amplification was performed on an ABI 7500 Real-Time PCR System (Applied Biosystems) at $95^{\circ} \mathrm{C}$ for $15 \mathrm{sec}$, followed by 40 cycles of $95^{\circ} \mathrm{C}$ for $5 \mathrm{sec}$, $60^{\circ} \mathrm{C}$ for $15 \mathrm{sec}$, and $72^{\circ} \mathrm{C}$ for $35 \mathrm{sec}$. The expression level of $p 66$ shc relative to that of the $\beta$-actin gene was calculated by the comparative threshold cycle (CT) method $\left(2^{-\Delta \Delta \mathrm{CT}}\right)$ [48].

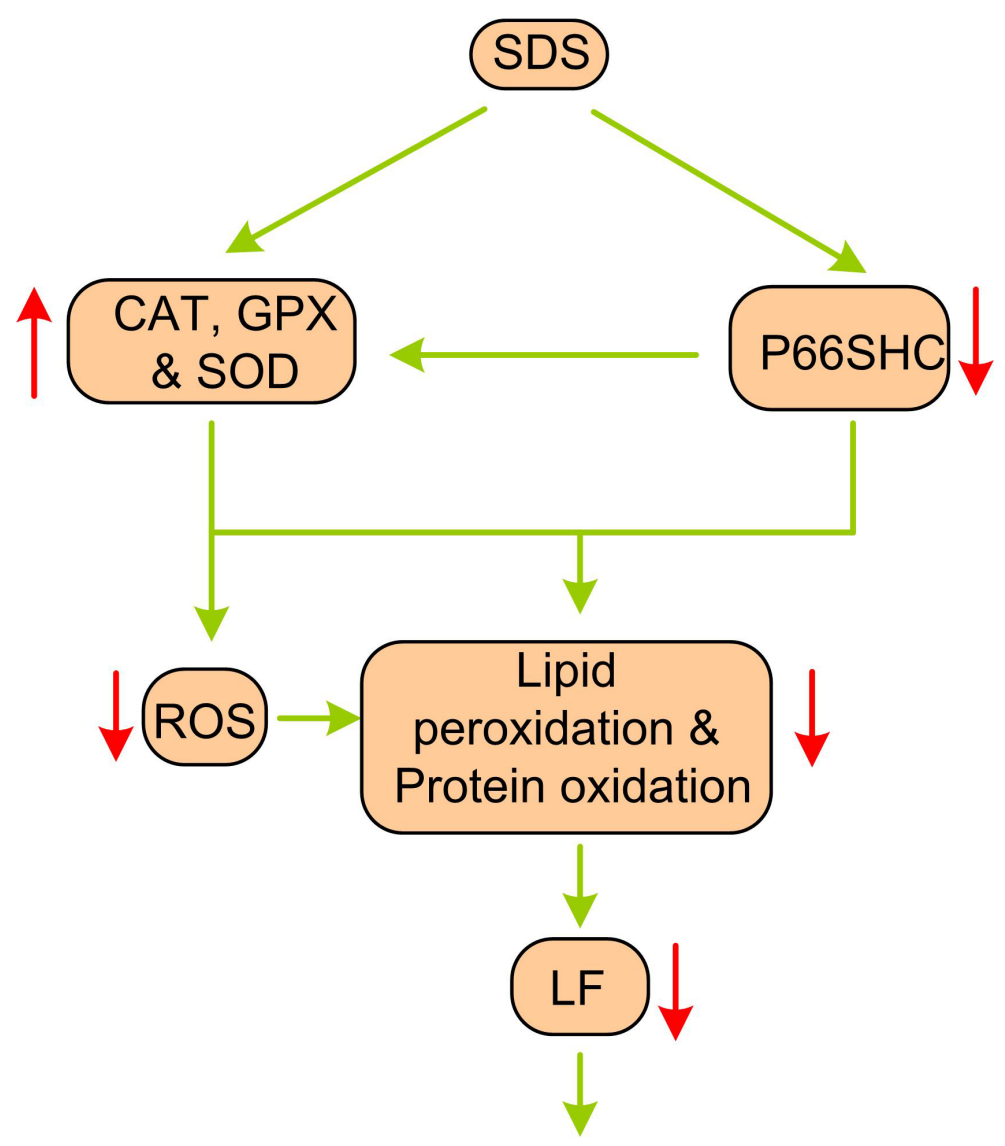

\section{Extension of lifespan}

Figure 8: A schematic diagram showing the potential mechanism of SDS administration on aging. The direction of arrows indicates the changes of biomarkers. 


\begin{tabular}{ll}
\hline \multicolumn{1}{c}{ Primers } & \multicolumn{1}{c}{ Sequences $\left(\mathbf{5}^{\prime} \mathbf{3}^{\prime} \mathbf{)}\right.$} \\
\hline For p66she cloning & \\
PS (sense) & ATGGAGCTCATGCAGAAAACCAAGT \\
PA (antisense) & TTAGGCCTTGCGCTCCACTGGCTGT \\
For qRT-PCR & \\
qPS (sense) & CCACCTTATGCTCCTTCTTCCCCAG \\
qPA (antisense) & CTGGGACTGCTGAGACCTGTTTGAG \\
$\beta$-actinS (sense) & CACCTTCTACAATGAGCTCCGT \\
$\beta$-actinA (antisense) & GCAGGAGTGTTGAAGGTCTCAA \\
For expression in eukaryotic vector & \\
ePS (sense) & \\
ePA (antisense) & GCC AAGCTT ATGGAGCTCATGCAGAAAACCAAGT \\
\hline
\end{tabular}

Sequences of the primers used in this study. The cutting sites of restriction enzyme were underlined

\section{Construction of eukaryotic expression vector}

For eukaryotic expression vector construction, the open reading frame of p66shc was amplified by PCR using the primers ePS with Hind III site and ePA with EcoR I site (Table 1), and sub-cloned into the plasmid expression vector pcDNA3.1/V5/His (Invitrogen), and the recombinant was designated $p c D N A 3.1 / p 66 s h c / V 5 / H i s$.

\section{Cell culture and transfection}

HEK 293T cells (gifts of Jianfeng Zhou, Laboratory of Molecular Medicine, School of Medicine and Pharmacy, Ocean University of China) were cultured at $37^{\circ} \mathrm{C}$ with $5 \% \mathrm{CO}_{2}$ in Dulbecco' modified Eagle medium (Invitrogen) supplemented with $10 \%(\mathrm{v} / \mathrm{v})$ fetal bovine serum (Invitrogen). They were seeded in 6-well plates and transfected with the different plasmids using Lipofectamine 2000 Reagent (Invitrogen) [49]. Briefly,

pcDNA3.1/p66shc/V5/His plasmid was mixed with Lipofectamine 2000, and the mixtures were added into HEK 293T cells and incubated at $37^{\circ} \mathrm{C}$ for $24 \mathrm{~h}$. Total Protein Extraction Kit (TRANSGEN, China) was used for preparation of total protein extracts from HEK 293T cells according to the manufacture's protocol. To further determine the expression of P66SHC, the proteins were subjected to Western blotting analysis. For control, HEK 293 T cells were either transfected with pcDNA3.1/V5/His or non-transfected at all, and then processed similarly.

\section{Western blotting}

A total of $1 \mathrm{~g}$ of the muscle from 4 freshly killed fish was homogenized in $5 \mathrm{ml}$ of $50 \mathrm{mM}$ PBS (pH7.5) containing the protease inhibitors, and centrifuged at $5000 \mathrm{~g}$ at $4^{\circ} \mathrm{C}$ for $10 \mathrm{~min}$. The proteins from $N$. guentheri muscles as well as the proteins extracted from HEK 293T cells were subjected to electrophoresis on a $12 \%$ sodium

Fish sampled
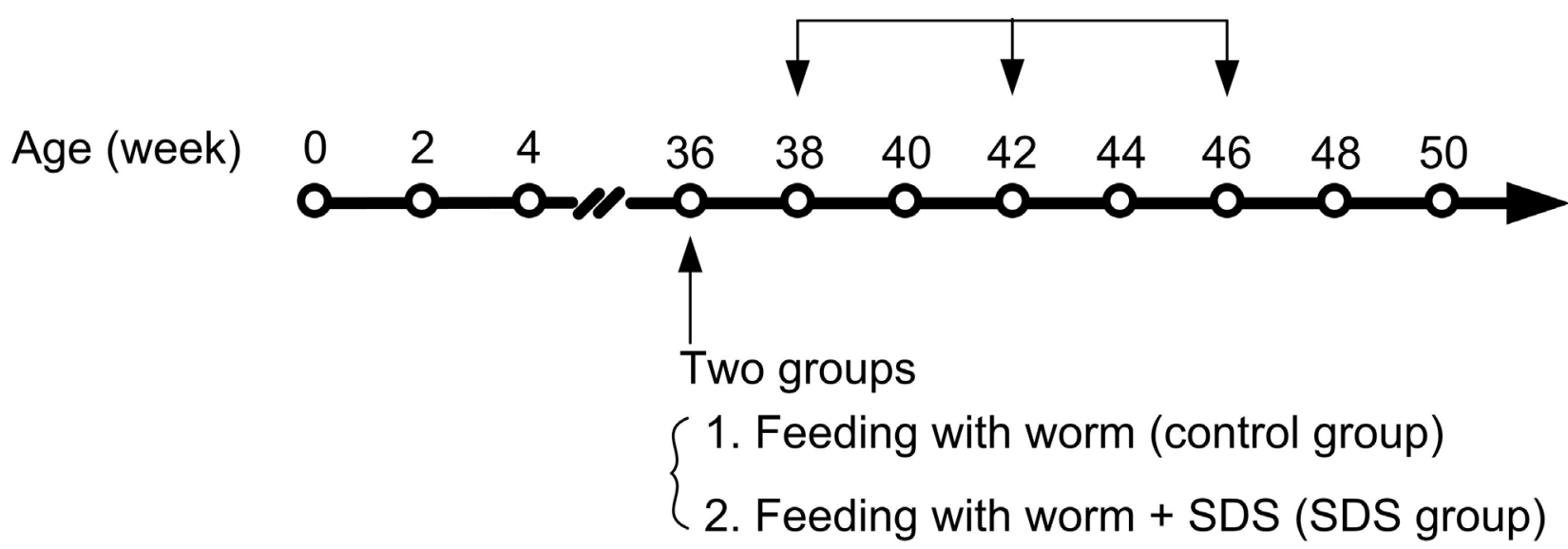

Figure 9: A schematic diagram of the experiments. The arrows indicate time points of feeding and sampling. SDS administration began with 36th week, and four fish were sampled from each group on 38th, 42th and 46th weeks. 
dodecyl sulfate polyacrylamide gel electrophoresis (SDSPAGE) gel (Each lane of the gel was loaded with $20 \mu \mathrm{g}$ of protein). The proteins on the gel were transferred to polyvinylidene difluoride (PVDF) membranes, which were blocked with $4 \%$ bovine serum albumin (BSA) in $10 \mathrm{mM}$ PBS (pH7.5) at room temperature for $2 \mathrm{~h}$. They were incubated with the following respective antibodies: anti-SHC polyclonal antibody (1:1000, ab155170; Abcam, UK), anti-His tag monoclonal antibody (1: 5000, CW0082B; CWBIO, China) and anti-Actin antibody (1:2000, bs-0061R; Bioss, China) at $4^{\circ} \mathrm{C}$ overnight. After washing in $10 \mathrm{mM}$ PBS (pH7.5) containing 0.1\% Tween-20, the membranes were then probed with a secondary horseradish peroxidase (HRP)-labeled antibody (1:3000) at room temperature for $3 \mathrm{~h}$. The bands were visualized by ECL Western blotting substrate (Thermo Fisher Scientific, USA) and analyzed using software Image J [50].

\section{Assay for ROS}

The quantitative determination of ROS was performed using dichloro-dihydro-fluorescein diacetate (DCFH-DA) as described by Dong et al. [51]. Aliquots of $1 \mathrm{~g}$ of the muscles (from 4 fish) were homogenized in 2.5 $\mathrm{ml}$ of $50 \mathrm{mM}$ PBS (pH7.5), centrifuged at $5000 \mathrm{~g}$ at $4^{\circ} \mathrm{C}$ for $30 \mathrm{~min}$, and the supernatants collected. The protein concentration of the supernatants was determined with a BCA Protein Assay Kit (CWBIO, China). A total of 1.8 $\mathrm{ml}$ of the supernatant with $1.8 \mathrm{mg}$ protein was mixed with $1.8 \mu \mathrm{l}$ of $10 \mathrm{mM}$ DCFH-DA (Beyotime, China), and the mixture incubated at $37^{\circ} \mathrm{C}$ for $30 \mathrm{~min}$. The fluorescence intensity was measured at excitation and emission wavelengths of $488 \mathrm{~nm}$ and $525 \mathrm{~nm}$.

\section{Statistical analysis}

Except fish culture, all the experiments were repeated at least three times. The single values for each replicas of the data were shown in Supplementary Table 2. Statistical analysis was performed using GraphPad Prism 5 program. All the data were expressed as mean \pm standard deviation (SD). The data regarding survival curves were subjected to the log-rank test. One-way ANOVA was used for the analysis of difference. Two-way ANOVA was used to estimate the interaction between two factors (age $\times$ treatment). A difference at $p<0.05$ was considered significant.

\section{ACKNOWLEDGMENTS}

This work was in part supported by the grants of Natural Science Foundation of Shandong Province (ZR2016CB23).

\section{CONFLICTS OF INTEREST}

No competing financial interests exist.

\section{REFERENCES}

1. Harman D. Aging: a theory based on free radical and radiation chemistry. J Gerontol. 1956; 11:298-300.

2. Finkel T, Holbrook NJ. Oxidants, oxidative stress and the biology of ageing. Nature. 2000; 408:239-247. https://doi. org/10.1038/35041687.

3. Jang YC, Van Remmen H. The mitochondrial theory of aging: insight from transgenic and knockout mouse models. Exp Gerontol. 2009; 44:256-260. https://doi.org/10.1016/j. exger.2008.12.006.

4. Loeb LA, Wallace DC, Martin GM. The mitochondrial theory of aging and its relationship to reactive oxygen species damage and somatic mtDNA mutations. Proc Natl Acad Sci USA. 2005; 102:18769-18770. https://doi. org/10.1073/pnas.0509776102.

5. Sohal RS, Weindruch R. Oxidative stress, caloric restriction, and aging. Science 1996; 273:59-63.

6. Beckman KB, Ames BN. Mitochondrial aging: open questions. Ann N Y Acad Sci. 1998; 854:118-127.

7. Larsen PL. Aging and resistance to oxidative damage in Caenorhabditis elegans. Proc Natl Acad Sci USA. 1993; 90:8905-8909.

8. Meng J, Lv Z, Qiao X, Li X, Li Y, Zhang Y, Chen C. The decay of Redox-stress Response Capacity is a substantive characteristic of aging: revising the redox theory of aging. Redox Biol. 2017; 11:365-374. https://doi.org/10.1016/j. redox.2016.12.026.

9. Collins JJ, Evason K, Kornfeld K. Pharmacology of delayed aging and extended lifespan of Caenorhabditis elegans. Exp Gerontol. 2006; 41:1032-1039.

10. Collins JJ, Evason K, Pickett CL, Schneider DL, Kornfeld $\mathrm{K}$. The anticonvulsant ethosuximide disrupts sensory function to extend C. elegans lifespan. PLoS Genet. 2008; 4:e1000230. https://doi.org/10.1371/journal.pgen.1000230.

11. Liu T, Qi H, Ma L, Liu Z, Fu H, Zhu W, Song T, Yang B, Li G. Resveratrol Attenuates Oxidative Stress and Extends Life Span in the Annual Fish Nothobranchius guentheri. Rejuvenation Res. 2015; 18:225-233. https:// doi.org/10.1089/rej.2014.1618.

12. Selman C, McLaren JS, Mayer C, Duncan JS, Collins AR, Duthie GG, Redman P, Speakman JR. Lifelong alphatocopherol supplementation increases the median life span of C57BL/6 mice in the cold but has only minor effects on oxidative damage. Rejuvenation Res. 2008; 11:83-96. https://doi.org/10.1089/rej.2007.0586.

13. Valenzano DR, Terzibasi E, Genade T, Cattaneo A, Domenici L, Cellerino A. Resveratrol prolongs lifespan and retards the onset of age-related markers in a short-lived vertebrate. Curr Biol. 2006; 16:296-300. 
14. Guan S, Wang W, Lu J, Qian W, Huang G, Deng X, Wang X. Salidroside attenuates hydrogen peroxideinduced cell damage through a cAMP-dependent pathway. Molecules. 2011; 16:3371-3379. https://doi.org/10.3390/ molecules 16043371.

15. Kanupriya, Prasad D, Sai Ram M, Kumar R, Sawhney RC, Sharma SK, Ilavazhagan G, Kumar D, Banerjee PK. Cytoprotective and antioxidant activity of Rhodiola imbricate against tert-butyl hydroperoxide induced oxidative injury in U-937 human macrophages. Mol Cell Biochem. 2005; 275:1-6. https://doi.org/10.1007/s11010005-7637-1.

16. Kelly GS. Rhodiola rosea: a possible plant adaptogen. Altern Med Rev. 2001; 6:293-302.

17. Lu L, Yuan J, Zhang S. Rejuvenating activity of salidroside (SDS): dietary intake of SDS enhances the immune response of aged rats. Age (Dordr). 2013; 35:637-646. https://doi.org/10.1007/s11357-012-9394-X.

18. Mao GX, Deng HB, Yuan LG, Li DD, Li YY, Wang Z. Protective role of salidroside against aging in a mouse model induced by D-galactose. Biomed Environ Sci. 2010; 23:161166. https://doi.org/10.1016/S0895-3988(10)60047-5.

19. Skopińska-Rózewska E, Malinowski M, Wasiutyński A, Sommer E, Furmanowa M, Mazurkiewicz M, Siwicki AK. The influence of Rhodiola quadrifida 50\% hydro-alcoholic extract and salidroside on tumor-induced angiogenesis in mice. Pol J Vet Sci. 2008; 11:97-104. https://doi. org/10.1016/j.freeradbiomed.2009.05.025.

20. Wang Q, Wang J, Sun LJ, Hu LP, Li J, Shao JQ, Lu B, Wang YT, Wu B, Wang GH. [Salidroside protects the hypothalamic-pituitary-gonad axis of male rats undergoing negative psychological stress in experimental navigation and intensive exercise]. [Article in Chinese]. Zhonghua Nan Ke Xue. 2009; 15:331-336.

21. Wu T, Zhou H, Jin Z, Bi S, Yang X, Yi D, Liu W. Cardioprotection of salidroside from ischemia/reperfusion injury by increasing $\mathrm{N}$-acetylglucosamine linkage to cellular proteins. Eur J Pharmacol. 2009; 613:93-99. https:// doi.org/10.1016/j.ejphar.2009.04.012.

22. Ye YC, Chen QM, Jin KP, Zhou SX, Chai FL, Hai P. [Effect of salidroside on cultured myocardial cells anoxia/ reoxygenation injuries]. [Article in Chinese]. Zhongguo Yao Li Xue Bao. 1993; 14:424-426.

23. Yu S, Liu M, Gu X, Ding F. Neuroprotective effects of salidroside in the PC12 cell model exposed to hypoglycemia and serum limitation. Cell Mol Neurobiol. 2008; 28:10671078. https://doi.org/10.1007/s10571-008-9284-z.

24. Zhang L, Yu H, Sun Y, Lin X, Chen B, Tan C, Cao G, Wang Z. Protective effects of salidroside on hydrogen peroxideinduced apoptosis in SH-SY5Y human neuroblastoma cells. Eur J Pharmacol. 2007; 564:18-25. https://doi. org/10.1016/j.ejphar.2007.01.089.

25. Zhu Y, Shi YP, Wu D, Ji YJ, Wang X, Chen HL, Wu SS, Huang DJ, Jiang W. Salidroside protects against hydrogen peroxide induced injury in cardiac H9c2 cells via PI3K-Akt dependent pathway. DNA Cell Biol. 2011; 30:809-819. https://doi.org/10.1089/dna.2010.1183.

26. Schriner SE, Abrahamyan A, Avanessian A, Bussel I, Maler S, Gazarian M, Holmbeck MA, Jafari M. Decreased mitochondrial superoxide levels and enhanced protection against paraquat in Drosophila melanogaster supplemented with Rhodiola rosea. Free Radic Res. 2009; 43:836-843. https://doi.org/10.1080/10715760903089724.

27. Hsu CY, Chiu YC, Hsu WL, Chan YP. Age-related markers assayed at different developmental stages of the annual fish Nothobranchius rachovii. J Gerontol A Biol Sci Med Sci. 2008; 63:1267-1276.

28. Genade T, Lang DM. Resveratrol extends lifespan and preserves glia but not neurons of the Nothobranchius guentheri optic tectum. Exp Gerontol. 2013; 48:202-212. https://doi.org/10.1016/j.exger.2012.11.013.

29. Genade T, Benedetti M, Terzibasi E, Roncaglia P, Valenzano DR, Cattaneo A, Cellerino A. Annual fishes of the genus Nothobranchius as a model system for aging research. Aging Cell. 2005; 4:223-233. https://doi.org/10.1111/ j.1474-9726.2005.00165.x.

30. Kemp FW, De Candia J, Li WJ, Bruening K, Baker H, Rigassio D, Bendich A, Bogden JD. Relationships between immunity and dietary and serum antioxidants, trace metals, B vitamins, and homocysteine in elderly men and women. Nutr Res. 2002; 22:45-53.

31. Meydani M, Meisler JG. A closer look at vitamin E. Can this antioxidant prevent chronic diseases? Postgrad Med. 1997; 102:199-201, 206-7. https://doi.org/10.3810/ pgm.1997.08.294.

32. Vidal K, Benyacoub J, Sanchez-Garcia J, Foata F, SeguraRoggero I, Serrant P, Moser M, Blum S. Intake of a milkbased wolfberry formulation enhances the immune response of young-adult and aged mice. Rejuvenation Res. 2010; 13:47-53.

33. Qi ZL, Liu YH, Qi SM, Ling LF, Feng ZY, Li Q. [Salidroside protects $\mathrm{PC} 12$ cells from $\mathrm{H}_{2} \mathrm{O}_{2}$-induced apoptosis via suppressing NOX2-ROS-MAPKs signaling pathway]. [Article in Chinese]. Nan Fang Yi Ke Da Xue Xue Bao. 2016; 37:178-183.

34. Yuan XY, Pang XW, Zhang GQ, Guo JY. Salidroside's Protection Against UVB-Mediated Oxidative Damage and Apoptosis Is Associated with the Upregulation of Nrf2 Expression. Photomed Laser Surg. 2017; 35:49-56. https:// doi.org/10.1089/pho.2016.4151.

35. Yang ZR, Wang HF, Zuo TC, Guan LL, Dai N. Salidroside alleviates oxidative stress in the liver with non- alcoholic steatohepatitis in rats. BMC Pharmacol Toxicol. 2016; 17:16. https://doi.org/10.1186/s40360-016-0059-8.

36. Si PP, Zhen JL, Cai YL, Wang WJ, Wang WP. Salidroside protects against kainic acid-induced status epilepticus via suppressing oxidative stress. Neurosci Lett. 2016; 618:1924. https://doi.org/10.1016/j.neulet.2016.02.056. 
37. Li F, Tang H, Xiao F, Gong J, Peng Y, Meng X. Protective effect of salidroside from Rhodiolae Radix on diabetesinduced oxidative stress in mice. Molecules. 2011; 16:9912-9924. https://doi.org/10.3390/molecules16129912.

38. Zhang W, Peng M, Yang Y, Xiao Z, Song B, Lin Z. Protective Effects of Salidroside on Mitochondrial Functions against Exertional Heat Stroke-Induced Organ Damage in the Rat. Evid Based Complement Alternat Med. 2015; 2015:504567. https://doi.org/10.1155/2015/504567.

39. Shi K, Wang X, Zhu J, Cao G, Zhang K, Su Z. Salidroside protects retinal endothelial cells against hydrogen peroxideinduced injury via modulating oxidative status and apoptosis. Biosci Biotechnol Biochem. 2015; 79:14061413. https://doi.org/10.1080/09168451.2015.1038212.

40. Markofsky J, Perlmutter A. Age at sexual maturity and its relationship to longevity in the male annual cyprinodont fish, Nothobranchius guentheri. Exp Gerontol. 1972; 7:131-135.

41. Markofsky J, Perlmutter A. Growth differences in subgroups of varying longevities in a laboratory population of the male annual cyprinodont fish, Nothobranchius guentheri (Peters). Exp. Gerontol. 1973; 8:65-73.

42. Sohal RS, Agarwal S, Dubey A, Orr WC. Protein oxidative damage is associated with life expectancy of houseflies. Proc Natl Acad Sci USA. 1993; 90:7255-7259.

43. Wang X, Chang Q, Wang Y, Su F, Zhang S. Late-onset temperature reduction can retard the aging process in aged fish via a combined action of an anti-oxidant system and the insulin/insulin-like growth factor 1 signaling pathway. Rejuvenation Res. 2014; 17:507-517. https://doi. org/10.1089/rej.2014.1581.

44. Okutan H, Ozcelik N, Yilmaz HR, Uz E. Effects of caffeic acid phenethyl ester on lipid peroxidation and antioxidant enzymes in diabetic rat heart. Clin Biochem. 2005; 38:191196. https://doi.org/10.1016/j.clinbiochem.2004.10.003.

45. Ursini F, Maiorino M, Gregolin C. The selenoenzyme phospholipid hydroperoxide glutathione peroxidase. Biochim Biophys Acta. 1985; 839:62-70.

46. Spitz DR, Oberley LW. An assay for superoxide dismutase activity in mammalian tissue homogenates. Anal Biochem. 1989; 179:8-18.

47. Chenna R, Sugawara H, Koike T, Lopez R, Gibson TJ, Higgins DG, Thompson JD. Multiple sequence alignment with the Clustal series of programs. Nucleic Acids Res. 2003; 31:3497-3500

48. Livak KJ, Schmittgen TD. Analysis of relative gene expression data using real-time quantitative PCR and the 2(-Delta Delta C(T)) Methods. 2001; 25:402-408.

49. Yang S, Liu S, Qu B, Dong Y, Zhang S. Identification of sea bass pIgR shows its interaction with vitellogenin inducing antibody-like activities in HEK 293 T cells. Fish Shellfish Immunol. 2017; 63:394-404. https://doi.org/10.1016/j. fsi.2016.12.001.

50. Dong Y, Cui P, Li Z, Zhang S. Aging asymmetry: systematic survey of changes in age-related biomarkers in the annual fish Nothobranchius guentheri. Fish Physiol Biochem. 2017; 43:309-319. https://doi.org/10.1007/s10695-0160288-1.

51. Dong M, Zhu L, Zhu S, Wang J, Wang J, Xie H, Du Z. Toxic effects of 1-decyl-3-methylimidazolium bromide ionic liquid on the antioxidant enzyme system and DNA in zebrafish Danio rerio livers. Chemosphere. 2013; 91:11071112. https://doi.org/10.1016/j.chemosphere.2013.01.013. 